\title{
Assessment of the Thickness of the Roof of the Glenoid Fossa Using Cone Beam Computed Tomography in Orthognathic Surgery Patients: A Preliminary Study
}

\author{
Hyun-Jeong Park ${ }^{1}$, Yo-Seob Seo ${ }^{2}$, Sung-Hoon Lim³ ${ }^{3}$ Ji-Won Ryu ${ }^{4}$ \\ 'Department of Oral Medicine, Chosun University Dental Hospital, Gwangju, Korea \\ ${ }^{2}$ Department of Oral and Maxillofacial Radiology, School of Dentistry, Chosun University, Gwangju, Korea \\ ${ }^{3}$ Department of Orthodontics, School of Dentistry, Chosun University, Gwangju, Korea \\ ${ }^{4}$ Department of Oral Medicine, School of Dentistry, Chosun University, Gwangju, Korea
}

Received November 24, 2019 Revised December 16, 2019 Accepted December 17, 2019
Correspondence to:

Ji-Won Ryu

Department of Oral Medicine, School of

Dentistry, Chosun University, 309 Pilmun-

daero, Dong-gu, Gwangju 61452, Korea

Tel: $+82-62-220-3897$

Fax: +82-62-234-2119

E-mail:dentian@chosun.ac.kr

https://orcid.org/0000-0002-5586-8195

This study was supported by research fund from Chosun University, 2016.
Purpose: The aim of this study was to assess the change in thickness of the roof of the glenoid fossa (RGF) in patients undergoing orthognathic surgery using cone-beam computed tomography (CBCT) images.

Methods: This retrospective study measured the thickness of the RGF in 19 patients (10 males, 9 females) who underwent orthognathic surgery at Chosun University Dental Hospital. The thickness of the RGF was measured perpendicularly between the 'glenoid fossa line' and 'middle cranial fossa line' on parasagittal and paracoronal reconstructions.

Results: The mean RGF thickness increased from $0.83 \pm 0.44 \mathrm{~mm}$ to $0.86 \pm 0.46 \mathrm{~mm}$ after surgery. The average change in thickness of the RGF was $0.17 \pm 0.18 \mathrm{~mm}$. The thickness of the RGF in the temporomandibular joint (TMJ) showed no significant difference by sex, and the change in thickness of the TMJ did not vary by surgical method.

Conclusions: We found that the thickness of the RGF increased after orthognathic surgery, as revealed by СBCT. Further studies including larger numbers of subjects and long-term follow-up are needed to confirm the results of this study.

Key Words: Cone-beam computed tomography; Orthognathic surgery; Roof of glenoid fossa; Temporomandibular joint

\section{INTRODUCTION}

The temporomandibular joint (TMJ), unlike other joints of the body, is very complicated, being composed of osseous components (condyles, glenoid fossa, and articular eminences) and soft tissues (articular discs and joint capsules) [1].

The marked thickness of the roof of the glenoid fossa (RGF) of the TMJ is important to withstand the various types of stimulation associated with facial trauma involving superior displacement of the mandibular condyle into the middle cranial fossa, as well as the effects of TMJ arthroplasty and joint reconstruction [2].

In general, orthognathic surgery is performed in patients with skeletal class II and III dentofacial deformities, and in patients with asymmetry. Orthognathic surgery includes one-jaw surgery (mandibular advancement or mandibular setback) and two-jaw surgery (bimaxillary advancement or setback). Orthognathic surgery affects the relationships of the soft tissues, as well as the osseous components of the TMJs [3,4].

Many studies have evaluated changes in condyle position and condyle shape after orthognathic surgery [3,57]. Cevidanes et al. [3] studied changes of the condyle of

Copyright (c) 2019 Korean Academy of Orofacial Pain and Oral Medicine. All rights reserved.

(cc) This is an open-access article distributed under the terms of the Creative Commons Attribution Non-Commercial License (http://creativecommons.org/licenses/by-nc/4.0/), which permits unrestricted non-commercial use, distribution, and reproduction in any medium, provided the original work is properly cited. 
the TMJs after orthognathic surgery, and reported surgical displacement and adaptive responses relative to adjacent structures in the craniofacial complex [3]. Skeletal stability differs depending on the orthognathic surgical method used. Busby et al. [6] and Proffit et al. [7] found that mandibular setback alone was more stable over the long term than when combined with maxillary surgery.

We suspect that not only changes in the condyle, but also in the morphology of the glenoid fossa, could be caused by orthognathic surgery. A previous study determined that the thickness of the RGF is clinically important [8]. This study evaluated changes in the glenoid fossa following orthognathic surgery using cone beam computed tomography (CBCT). CBCT images, which can be obtained relatively economically and involve lower radiation doses, have proven remarkably useful in craniofacial investigations [3]. The aim of this study was to assess the change in thickness of the RGF in patients undergoing orthognathic surgery.

\section{MATERIALS AND METHODS}

\section{Subjects}

This study included patients who underwent orthognathic surgery at the Oral and Maxillofacial Surgery Department of Chosun University Dental Hospital. Patients were diagnosed with mandibular prognathism, retrognathism, or asymmetry underwent one-jaw surgery (mandibular setback or advancement) or two-jaw surgery (maxillomandibular setback or advancement). The total number of patients undergoing orthognathic surgery from January 2015 to September 2019 was 104. However, only 19 patients (10 males, 9 females; mean age, $26.5 \pm 6.7$ years) were selected, due to the exclusion of those without postoperative CBCT data, a truncated TMJ on CBCT images, or temporomandibular disorder prior to surgery. This retrospective study was approved by the Institutional Review Committee of Chosun University Dental Hospital (CUDH) (IRB no. 1901/013).

\section{Image Analysis}

Images of the glenoid fossa of the temporal bone were edited using three-dimensional imaging software (OnDemand3D; CyberMed Co., Seoul, Korea). As in a previous study [8], the images were reconstructed based on the angle of the condylar head. Paracoronal sections were obtained parallel to the horizontal axis of the condylar head, and parasagittal sections were reconstructed parallel to the line connecting the center point of the condylar head with the coronoid process (1 mm slice thickness, $1 \mathrm{~mm}$ slice interval). The reconstructed data sets were exported as Digital Imaging and Communications in Medicine image stacks.

\section{Measurement of the Thickness of the Roof of the Glenoid Fossa}

The method used for measuring RGF thickness was the same as in previous studies [8]. Measurements were obtained on images of the central region of the glenoid fossa in parasagittal and paracoronal sections using G3 software (Infinitt Healthcare, Seoul, Korea). The images were assessed

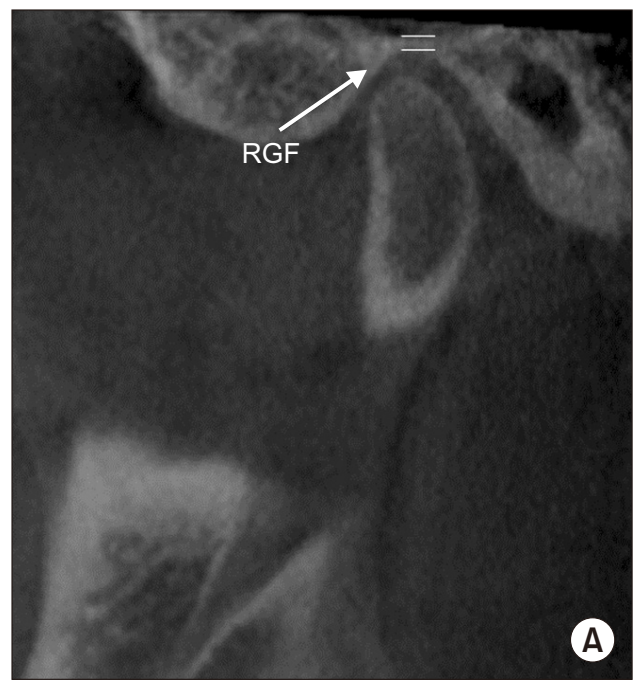

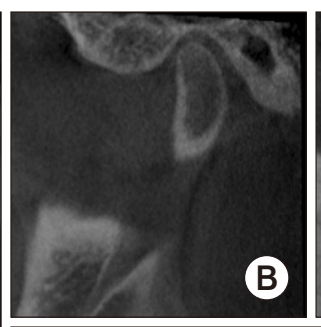
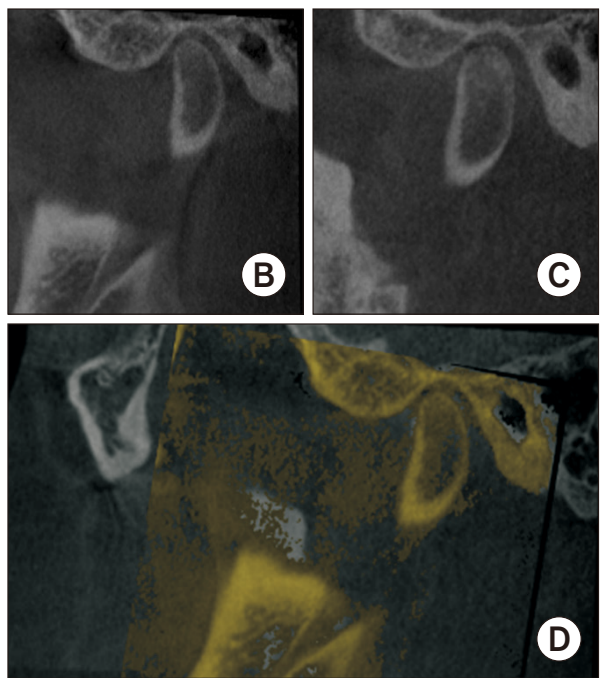

Fig. 1. Parasagittal reconstruction of cone beam computed tomography images. (A) Roof of the glenoid fossa (RGF), thickness of the Roof of glenoid fossa. (B) Thickness of the RFG before orthognathic surgery. (C) Thickness of the RGF after orthognathic surgery. (D) A super-imposition of images before and after orthognathic surgery. Preoperative image for yellow color, postop image for grey color. 
in a darkened room on a personal computer with a 32-inch LCD monitor. The contrast and brightness of the images were adjusted using the image processing tool of G3 to ensure optimal visualization. The thickness of the RGF was determined as the perpendicular distance between the 'glenoid fossa line' and 'middle cranial fossa line' on parasagittal (Fig. 1) and paracoronal reconstructions. RGF thickness was measured three times, by one investigator, at the thinnest part of the glenoid fossa among multiple slices, with the mean value calculated for statistical analysis. The same examiner measured the thickness of the RGF, in the same way as in a previous study [8], therefore, interexaminer agreement was not assessed in this study.

\section{Statistical Analysis}

Statistical analyses were performed using PASW Statistics for Windows, Version 18.0 (SPSS Inc., Chicago, IL, USA). The Shapiro-Wilk test was used to test the normality of the data distribution. A p-value $<0.05$ was regarded as statistically significant. All quantitative variables are described as means \pm standard deviations. In a previous study [8], intraand interexaminer agreement with respect to RGF thickness was evaluated using the intraclass correlation coefficient. Comparison of the RGF thickness of patients pre-and postsurgery, and analyses of RGF thickness according to sex and surgical method, were performed using t-tests.

\section{RESULTS}

This study involved 19 patients (10 males and 9 females) who underwent corrective surgery (Table 1). The mean age was 26.5 \pm 6.7 years (Table 1). Increases in RGF thickness were observed in all 19 patients (Table 2). The mean RGF thickness increased from $0.83 \pm 0.44 \mathrm{~mm}$ to $0.86 \pm 0.46 \mathrm{~mm}$

Table 1. Patients demographic data

\begin{tabular}{lc}
\hline Variable & Value \\
\hline Age & $26.5 \pm 6.7$ \\
Sex & 10 \\
Male & 9 \\
Female & \\
Surgical method & 11 \\
1-Jaw surgery & 8 \\
2-Jaw surgery & \\
\hline
\end{tabular}

Values are presented as mean \pm standard deviation or number only.

Table 2. The thickness of the RGF on pre- and post-surgery (unit: mm)

\begin{tabular}{|c|c|c|c|c|c|c|c|c|}
\hline \multirow{3}{*}{$\begin{array}{c}\text { Position } \\
1\end{array}$} & \multicolumn{4}{|c|}{ Sagittal $(n=19)$} & \multicolumn{4}{|c|}{ Coronal $(n=19)$} \\
\hline & \multicolumn{2}{|c|}{ Rt. (before/after) } & \multicolumn{2}{|c|}{ Lt. (before/after) } & \multicolumn{2}{|c|}{ Rt. (before/after) } & \multicolumn{2}{|c|}{ Lt. (before/after) } \\
\hline & 0.58 & 0.68 & 1.17 & 1.26 & 0.68 & 0.78 & 1.02 & 1.22 \\
\hline 2 & 0.40 & 0.59 & 0.39 & 0.49 & 0.40 & 0.68 & 0.52 & 0.78 \\
\hline 3 & 0.78 & 1.01 & 0.68 & 0.78 & 0.88 & 1.02 & 0.56 & 0.88 \\
\hline 4 & 1.26 & 1.65 & 0.58 & 0.69 & 1.26 & 1.95 & 0.68 & 0.88 \\
\hline 5 & 1.17 & 1.46 & 0.68 & 0.78 & 1.14 & 1.44 & 0.52 & 0.73 \\
\hline 6 & 0.40 & 0.57 & 0.68 & 1.20 & 0.50 & 0.63 & 0.74 & 1.26 \\
\hline 7 & 0.76 & 0.78 & 0.68 & 0.90 & 0.79 & 0.78 & 0.88 & 1.18 \\
\hline 8 & 0.68 & 0.74 & 0.68 & 0.80 & 0.68 & 0.78 & 0.69 & 0.80 \\
\hline 9 & 0.98 & 1.05 & 1.19 & 1.35 & 0.88 & 1.02 & 1.19 & 1.39 \\
\hline 10 & 1.67 & 2.23 & 2.20 & 2.92 & 1.48 & 2.37 & 2.40 & 2.98 \\
\hline 11 & 0.54 & 0.61 & 0.75 & 0.78 & 0.59 & 0.73 & 0.68 & 0.72 \\
\hline 12 & 0.69 & 0.84 & 0.63 & 0.71 & 0.60 & 0.88 & 0.70 & 0.85 \\
\hline 13 & 0.55 & 0.73 & 0.45 & 0.67 & 0.58 & 0.71 & 0.50 & 0.71 \\
\hline 14 & 0.69 & 0.73 & 0.74 & 0.74 & 0.56 & 0.69 & 0.68 & 0.69 \\
\hline 15 & 0.81 & 0.66 & 1.14 & 1.17 & 0.74 & 0.58 & 1.14 & 1.16 \\
\hline 16 & 0.52 & 0.51 & 0.49 & 0.59 & 0.43 & 0.52 & 0.59 & 0.60 \\
\hline 17 & 0.33 & 0.42 & 0.33 & 0.39 & 0.33 & 0.43 & 0.33 & 0.40 \\
\hline 18 & 0.58 & 0.60 & 0.41 & 0.56 & 0.51 & 0.66 & 0.50 & 0.58 \\
\hline 19 & 0.68 & 0.76 & 0.85 & 0.88 & 0.73 & 0.84 & 0.79 & 0.87 \\
\hline Total & $0.74 \pm 0.33$ & $0.87 \pm 0.45$ & $0.77 \pm 0.43$ & $0.93 \pm 0.55$ & $0.72 \pm 0.30$ & $0.92 \pm 0.49$ & $0.80 \pm 0.45$ & $0.98 \pm 0.55$ \\
\hline
\end{tabular}

RGF, roof of glenoid fossa; Rt., right ; Lt., left.

Values are presented as distance or mean \pm standard deviation only. 
after surgery (Table 3). The average change in thickness of the RGF was $0.17 \pm 0.18 \mathrm{~mm}$ (Table 4).

The change in thickness of the RGF on parasagittal and paracoronal images showed no significant difference by sex (Table 5).

In total, 8 of 19 patients underwent two-jaw surgery (7 patients underwent maxillary LeFort 1 surgery and mandibular setback, and 1 underwent maxillary and mandibular advancement), and 11 patients underwent one-jaw surgery (mandibular setback) (Table 1). There was no significant difference in the change in thickness of the TMJ according to surgical method (one- vs. two-jaw surgery) (Table 6).

\section{DISCUSSION}

The TMJ is affected by the surrounding environment [9]. Factors contributing to changes in the structure of the TMJ include disc derangement, degenerative arthritis and orthognathic surgery [9].

CBCT is a highly efficient and low-cost imaging modality suitable for observing bone changes [10]. In particular, since the radiation dose is lower than that of conventional CT, CBCT can be performed several times over the follow-up period [10]. In general, CBCT is used to accurately evaluate skeletal structure, devise a surgical plan before orthognathic surgery, and evaluate skeletal changes during follow-up $[3,10]$. We analyzed before- and after-surgery CBCT images using three-dimensional imaging software in our evaluation of the skeletal structure of the TMJ.

In this study, the thickness of the RGF was not significantly different from the value for Koreans obtained in a previous study [8]. We evaluated the change in thickness (pre- vs. post-surgery) of the RGF on CBCT images in patients who underwent orthognathic surgery. The average thickness of the RGF increased from $0.83 \pm 0.44 \mathrm{~mm}$ to $0.86 \pm 0.46 \mathrm{~mm}$ (Table 3). There have been many studies of changes in the condyle and glenoid fossa of TMJs after orthognathic surgery [11-15]. Cottrell et al. [11] reported minimal long-term changes in healthy patients after orthognathic surgery. An et al. [12] noted that surgical correction of skeletal deformities requires a soft-tissue response and condylar remodeling, to adapt to the new environment. They noted condylar

Table 4. The change amount of the thickness of the RGF on preand post-surgery

\begin{tabular}{|c|c|c|c|c|}
\hline \multirow{2}{*}{ Position } & \multicolumn{2}{|c|}{ Sagittal $(n=19)$} & \multicolumn{2}{|c|}{ Coronal $(n=19)$} \\
\hline & Rt. (mm) & Lt. (mm) & Rt. (mm) & Lt. (mm) \\
\hline 1 & 0.10 & 0.09 & 0.10 & 0.20 \\
\hline 2 & 0.19 & 0.10 & 0.28 & 0.26 \\
\hline 3 & 0.23 & 0.10 & 0.14 & 0.32 \\
\hline 4 & 0.39 & 0.11 & 0.69 & 0.20 \\
\hline 5 & 0.29 & 0.10 & 0.30 & 0.21 \\
\hline 6 & 0.17 & 0.52 & 0.13 & 0.52 \\
\hline 7 & 0.02 & 0.22 & -0.01 & 0.30 \\
\hline 8 & 0.06 & 0.12 & 0.10 & 0.11 \\
\hline 9 & 0.07 & 0.16 & 0.14 & 0.20 \\
\hline 10 & 0.56 & 0.72 & 0.89 & 0.58 \\
\hline 11 & 0.07 & 0.03 & 0.14 & 0.04 \\
\hline 12 & 0.15 & 0.08 & 0.28 & 0.15 \\
\hline 13 & 0.18 & 0.22 & 0.13 & 0.21 \\
\hline 14 & 0.04 & 0.00 & 0.13 & 0.01 \\
\hline 15 & -0.15 & 0.03 & -0.16 & 0.02 \\
\hline 16 & -0.01 & 0.10 & 0.09 & 0.01 \\
\hline 17 & 0.09 & 0.06 & 0.10 & 0.07 \\
\hline 18 & 0.02 & 0.15 & 0.15 & 0.08 \\
\hline 19 & 0.08 & 0.03 & 0.11 & 0.08 \\
\hline Total & $0.13 \pm 0.16$ & $0.15 \pm 0.18$ & $0.20 \pm 0.23$ & $0.18 \pm 0.16$ \\
\hline
\end{tabular}

RGF, roof of glenoid fossa; Rt., right ; Lt., left.

Values are presented as distance or mean \pm standard deviation only.

Table 3. The mean of the thickness of RGF on pre- and post surgery

\begin{tabular}{|c|c|c|c|c|c|c|c|c|}
\hline \multirow{3}{*}{ Position } & \multicolumn{4}{|c|}{ Pre-surgery $(n=19)$} & \multicolumn{4}{|c|}{ Post-surgery $(n=19)$} \\
\hline & \multicolumn{2}{|c|}{ Rt. (mm) } & \multicolumn{2}{|c|}{ Lt. (mm) } & \multicolumn{2}{|c|}{ Rt. (mm) } & \multicolumn{2}{|c|}{ Lt. (mm) } \\
\hline & Sagittal & Cononal & Sagittal & Cononal & Sagittal & Cononal & Sagittal & Cononal \\
\hline $\begin{array}{l}\text { Mean value according to } \\
\text { position }\end{array}$ & $0.74 \pm 0.33$ & $0.72 \pm 0.30$ & $0.77 \pm 0.43$ & $0.80 \pm 0.45$ & $0.87 \pm 0.45$ & $0.92 \pm 0.49$ & $0.93 \pm 0.55$ & $0.98 \pm 0.55$ \\
\hline Total mean value & \multicolumn{4}{|c|}{$0.83 \pm 0.44$} & \multicolumn{4}{|c|}{$0.86 \pm 0.46$} \\
\hline $\begin{array}{l}\text { Mean value of } \\
\text { change amount }\end{array}$ & \multicolumn{8}{|c|}{$0.17 \pm 0.18$} \\
\hline
\end{tabular}

RGF, roof of glenoid fossa; Rt., right ; Lt., left.

Values are presented as mean \pm standard deviation. 
Table 5. Differences between male and female about orthognathic surgery patients

\begin{tabular}{lllll}
\hline Sex & Rt. coronal & Lt. coronal & Rt. sagittal & Lt. sagittal \\
\hline Male & $0.26 \pm 0.29$ & $0.21 \pm 0.20$ & $0.15 \pm 0.18$ & $0.22 \pm 0.23$ \\
Female & $0.13 \pm 0.13$ & $0.16 \pm 0.11$ & $0.11 \pm 0.13$ & $0.09 \pm 0.06$ \\
\hline
\end{tabular}

RGF, roof of glenoid fossa; Rt., right; Lt., left.

Statistically significant difference $(p<0.05)$ (t-test).

Table 6. Differences according to surgical methods (1-jaw/2-jaw surgery)

\begin{tabular}{ccc}
\hline Surgical method & $\begin{array}{c}\text { 1-jaw surgery } \\
(0.17 \pm 0.18)\end{array}$ & $\begin{array}{c}\text { 2-jaw surgery } \\
(0.15 \pm 0.18)\end{array}$ \\
\hline 1- jaw surgery $(0.17 \pm 0.18)$ & - & - \\
2- jaw surgery $(0.15 \pm 0.18)$ & $0.496^{\star}$ & - \\
\hline
\end{tabular}

*Statistically significant difference $(p<0.05)$ (t-test).

surface changes, and reported that condylar inward rotation was closely related to changes in the condylar surface [12]. Kim et al. [13] reported that orthognathic surgery was able to correct dentofacial deformities and alter the neuromuscular environment. They noted that surgical correction led to a physiological adaptation process, according to changes in the position of the condyle [13]. Owtad et al. [14] reported that the glenoid fossa was remodeled according to changes in the surrounding environment, likely involving the condyle. Kai et al. [15] showed that the RGF was thicker in patients with versus without degenerative joint changes and disc displacement. They suggested that this may be attributable to remodeling, or might occur in response to mechanical stress [15].

Many studies have reported bone changes, such as flattening and rotation of the condyle, after orthognathic surgery $[16,17]$. We suggest that these changes in the surface and location of the condyle also affect the glenoid fossa of the TMJ. The increase in thickness of the RFG seen in this study showed that structural changes and mechanical stress after surgery affected the glenoid fossa of the TMJ [17].

There was no significant difference in the thickness of the RGF according to sex (Table 5). These results are consistent with previous studies showing that the thickness of the RGF is not affected by age or sex $[2,18]$.

In this study, 11 of 19 patients underwent one-jaw surgery (mandibular setback), while 8 patients underwent two-jaw (maxillary) surgery (Table 6). There was no significant difference in the variation in thickness of the TMJ according to the surgical method (Table 6). An et al. [12] reported no significant difference in the extent of remodeling of the constant bone between one- and two-jaw surgeries. However, Wolford et al. [17] reported greater bone remodeling in two- versus one-jaw surgery. In one-jaw surgery, there is a difference in the position of the condyle, and the stress applied to the glenoid fossa, according to whether mandibular setback or advancement is performed [3,5,17]. Wolford et al. [17] reported that physiological adaptation is difficult when surgical correction is performed in the counterclockwise direction.

There were several limitations to our study. First, the small sample size makes it difficult to generalize the results. Also, Koreans typically have a class III skeletal structure $[19,20]$. In this study, only one patient had a class II skeletal structure (Table 6). In addition, many studies have shown that bone to remodeling after surgery can take a relatively long time [21,22]; however, in our study, CT was performed only about 1 year after surgery. Therefore, long-term follow-up should be implemented in future studies to assess bone remodeling.

In conclusion, we found that the thickness of the RGF increased after orthognathic surgery, as revealed by CBCT. Further studies including larger numbers of subjects and long-term follow-up are needed to confirm the results of this study.

\section{CONFLICT OF INTEREST}

No potential conflict of interest relevant to this article was reported.

\section{ORCID}

Hyun-Jeong Park

http://orcid.org/0000-0002-5237-005X 


\author{
Yo-Seob Seo \\ http://orcid.org/0000-0003-1804-5648 \\ Sung-Hoon Lim \\ http://orcid.org/0000-0003-4528-8514 \\ Ji-Won Ryu \\ http://orcid.org/0000-0002-5586-8195
}

\section{REFERENCES}

1. Bag AK, Gaddikeri S, Singhal A, et al. Imaging of the temporomandibular joint: an update. World J Radiol 2014;6:567-582.

2. Honda K, Kawashima S, Kashima M, Sawada K, Shinoda K, Sugisaki M. Relationship between sex, age, and the minimum thickness of the roof of the glenoid fossa in normal temporomandibular joints. Clin Anat 2005;18:23-26.

3. Cevidanes LH, Bailey LJ, Tucker SF, et al. Three-dimensional cone-beam computed tomography for assessment of mandibular changes after orthognathic surgery. Am J Orthod Dentofacial Orthop 2007;131:44-50.

4. Motta AT, Cevidanes LH, Carvalho FA, Almeida MA, Phillips C. Three-dimensional regional displacements after mandibular advancement surgery: one year of follow-up. J Oral Maxillofac Surg 2011;69:1447-1457.

5. Vandeput AS, Verhelst PJ, Jacobs R, Shaheen E, Swennen G, Politis C. Condylar changes after orthognathic surgery for class III dentofacial deformity: a systematic review. Int J Oral Maxillofac Surg 2019;48:193-202.

6. Busby BR, Bailey LJ, Proffit WR, Phillips C, White RP Jr. Longterm stability of surgical class III treatment: a study of 5-year postsurgical results. Int J Adult Orthodon Orthognath Surg 2002;17:159-170.

7. Proffit WR, Bailey LJ, Phillips C, Turvey TA. Long-term stability of surgical open-bite correction by Le Fort I osteotomy. Angle Orthod 2000;70:112-117.

8. Park HJ, Seo YS, Yoon A, Kim JH, Ryu JW. Assessment of the thickness of the roof of the glenoid fossa using cone beam computed tomography in asymptomatic Korean adult patients. J Oral Med Pain 2019;44:112-117.

9. Wadhwa S, Kapila S. TMJ disorders: future innovations in diagnostics and therapeutics. J Dent Educ 2008;72:930-947.

10. Sukovic P. Cone beam computed tomography in craniofacial imaging. Orthod Craniofac Res 2003;6 Suppl 1:31-36; discussion 179-182.

11. Cottrell DA, Suguimoto RM, Wolford LM, Sachdeva R, Guo IY. Condylar change after upward and forward rotation of the maxillomandibular complex. Am J Orthod Dentofacial Orthop 1997;111:156-162.

12. An SB, Park SB, Kim YI, Son WS. Effect of post-orthognathic surgery condylar axis changes on condylar morphology as determined by 3-dimensional surface reconstruction. Angle Orthod 2014;84:316-321.

13. Kim YI, Cho BH, Jung YH, Son WS, Park SB. Cone-beam computerized tomography evaluation of condylar changes and stability following two-jaw surgery: Le Fort I osteotomy and mandibular setback surgery with rigid fixation. Oral Surg Oral Med Oral Pathol Oral Radiol Endod 2011;111:681-687.

14. Owtad P, Park JH, Shen G, Potres Z, Darendeliler MA. The biology of TMJ growth modification: a review. J Dent Res 2013;92:315321.

15. Kai Y, Matsumoto K, Ejima K, Araki M, Yonehara Y, Honda K. Evaluation of the usefulness of magnetic resonance imaging in the assessment of the thickness of the roof of the glenoid fossa of the temporomandibular joint. Oral Surg Oral Med Oral Pathol Oral Radiol Endod 2011;112:508-514.

16. Yamada K, Hanada K, Hayashi T, Ito J. Condylar bony change, disk displacement, and signs and symptoms of TMJ disorders in orthognathic surgery patients. Oral Surg Oral Med Oral Pathol Oral Radiol Endod 2001;91:603-610.

17. Wolford LM, Reiche-Fischel 0, Mehra P. Changes in temporomandibular joint dysfunction after orthognathic surgery. J Oral Maxillofac Surg 2003;61:655-660; discussion 661.

18. Lobo F, Tolentino ES, Iwaki LCV, Walewski LÂ, Takeshita WM, Chicarelli M. Imaginology tridimensional study of temporomandibular joint osseous components according to sagittal skeletal relationship, sex, and age. J Craniofac Surg 2019;30:1462-1465.

19. Ong MA. Spectrum of dentofacial deformities: a retrospective survey. Ann Acad Med Singapore 2004;33:239-242.

20. Ruslin M, Forouzanfar T, Astuti IA, Soemantri ES, Tuinzing DB. The anthropological aspects of dentofacial deformities: a comparison between Indonesian and Dutch cohorts (aspek antropologi kelainan bentuk dentofasial: sebuah perbandingan antara kelompok Indonesia dan Belanda). J Dentomaxillofac Sci 2014;13:4854.

21. Hoppenreijs TJ, Stoelinga PJ, Grace KL, Robben CM. Longterm evaluation of patients with progressive condylar resorption following orthognathic surgery. Int J Oral Maxillofac Surg 1999;28:411-418.

22. Hwang SJ, Haers PE, Zimmermann A, Oechslin C, Seifert B, Sailer HF. Surgical risk factors for condylar resorption after orthognathic surgery. Oral Surg Oral Med Oral Pathol Oral Radiol Endod 2000;89:542-552. 